\title{
Percursos de um Arq-Vivo: entre arquivos e experiências na pesquisa em História da Educação
}

Paths of a Living-Archive: between archives and experiences in the History Education research

Caminos de un Arch-Vivo: entre archivos y experiencias en la investigación en Historia de la Educación

Marcos Epifanio Barbosa Lima Universidade Vale do Rio dos Sinos (Brasil)

https://orcid.org/0000-0001-8593-7254

http://lattes.cnpq.br/9848315028689294 amdgsj@gmail.com

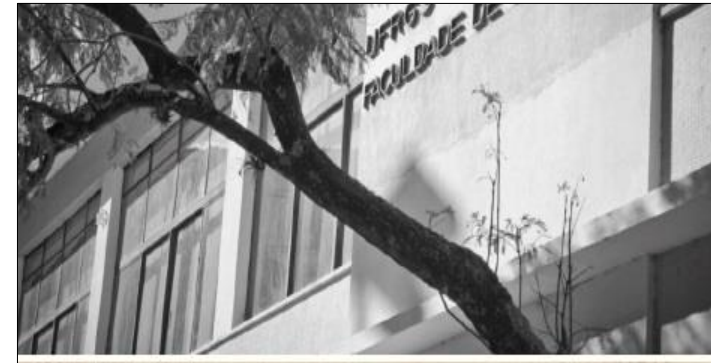

Percursos de um Arq-Vivo: entre arquivos e experiências na pesquisa em História da Educação

Dóris Bittencourt Almeida

\section{LLetral}

ALMEIDA, Doris Bittencourt. Percursos de um Arq-Vivo: entre arquivos e experiências em História da Educação. Porto Alegre: Letra 1, 2021. 164p. 
O livro 'Percursos de um Arq-Vivo: entre arquivos e experiências na pesquisa em História da Educação' é fruto do projeto de pesquisa doutoral da Profa. Dra. Dóris Bittencourt Almeida - almeida.doris@ gmail.com - cujo caminho formativo, docente e investigativo circula entre chefias editorias em revistas da área de história, liderança e vice-liderança em grupos e linhas de pesquisa CNPq e IES e participação em grupos internacionais latino-americano nas áreas de concentração História/Educação/ Memória/ Patrimônio.

Já do título, esmeradamente composto, denota-se o cuidado com a intencionalidade do material e das reflexões que delas se oriundam, quando a autora nos apresenta uma espécie de silogismo - com duas expressões que dão vida a uma terceira ideia. Muito mais que um jogo de jogo de palavras e fonéticas entre 'arquivo' e 'vivo', esta nova formulação - 'Arq-Vivo' que toca a raiz mesma do que a autora pretende em sua obra: fazer tessituras, criações analíticas e caracterização de uma historiografia do tempo, dividindo o material em duas partes.

A primeira parte - "Raspas e restos me interessam" -, organizada em três capítulos, nos apresenta o estudo e análise sobre como o cuidado com o arquivamento institucional é fundamental para criação de memória, focando na experiência da própria autora na FACED- UFRGS.

Em seu primeiro capítulo (pp. 16-30) trata dos Arquivos como questão por meio das moradas para memórias em papel (pp. 19-23) e das dimensões do guardar e do pesquisar em Arquivos (pp. 23-30). Da ênfase quanto ao guardar e pesquisar em arquivo, mais que um catalogar documentos frios, trata-se de envolver-se com um capital de experiências sobre velhos papeis, em um voltar no tempo o qual não se mantém apenas no ano específico do início da pesquisa, mas percorre-se várias décadas anteriores que os próprios materiais de pesquisa instam a visitar em marca de temporalidade memorial, imaginativa e investigativa. Ainda neste capítulo se reflete que o gesto de guardar deve ser refinado de modo a produzir, provocar e desencadear lembranças, meditações e mediações, buscas, preocupações e afetos, trajetórias, ausências e produções sobre o tempo.

No segundo capítulo, o foco do estudo concerta-se no caminhar pelas tramas das memórias orais: arquivar para eternizar (pp. 31-39). Aqui se expõem os processos e resultados de entrevistas como evento sensível para a ebulição de narratividades em camadas temporais com professores e técnicos dos espaços de empiria escolhidos - a FACED-UFRGS e o Colégio de Aplicação - onde os sujeitos narradores são convidados a remexerem em seus passados com o intuito de produção de memórias orais.

Já o capítulo terceiro avança com a temática resguardando a composição presente entre cadernos, agendas, recortes, correspondências e bilhetes com o intuito de expor, registar e analisar sensibilidades em arquivos pessoais (pp. 41-59). Destaca-se aqui, como uma das fontes principais, os documentos pessoais de professores sem a pretensão de encontrar o eu coerente, mas sim buscar ir além das previsibilidades, das aparências e superfícies dos atos em seus registros, para se deparar com possíveis contradições e transgressões. Tal abordagem torna ainda mais rico o livro aqui resenhado uma vez que, com tal proposta de análise crítica dos dados a partir da História Oral, há o interesse em se confirmar o afastamento de uma possível escrita laudatória aos pesquisados por parte do pesquisador, em constante estado de atenção à sedução que o arquivo privado pode gerar no autor que sobre ele se debruça.

Segue-se ainda neste mesmo capítulo terceiro os comentários quanto ao conjunto de documentos doados pelos professores que passaram a compor o arquivo institucional da FACED-UFRGS através dos esforços e abordagens da autora. Podemos nesta secção acompanhar o caminho dos arquivos pessoais dos seguintes professores: Luzia Garcia de Mello (p. 44); Isabel Loss (p. 45); Balduino Andreola (p. 46); Alceu Ferraro (p.46); Maria Helena Camara Bastos (p.46); Tania Ramos Fortuna (p.47); e Beatriz Daudt Fischer (p.47); Nilton Bueno Fischer (p. 49). A conclusão do capítulo dá a conhecer como o arquivo desta Instituição é um setor da FACED/UFRGS que abriga rastros, restos e sinais do passado vivo como substratos prontos para se tornarem outras construções em linha de trama histórica. 
Um destaque especial, que reflete o cuidado da autora em reforçar o seu texto como um documento referenciado em outras tantas leituras e estudos por ela praticados e em vista a ajudar seus leitores no caminho epistemológico então traçado, é que há a elaboração dos referenciais bibliográficos não no final do livro, mas em uma local específica já no encerramento da primeira parte (pp. 54-59).

Convém evidenciar também que tal proposição em referendar os estudos feitos através de bibliografia focal e específica também se encontra na Parte Dois do livro, porém de modo ainda mais refinado, apresentando bibliografias específicas ao final de cada um dos quatro capítulos que compõem tal parte.

A segunda parte - "De memórias fizeram-se histórias" (pp. 61-159) -, em marca de ligação com a primeira, destacam-se os espaços, as materialidades, os vínculos e os métodos personalizados de arquivamento memorial de docentes na construção da pesquisa científica e acadêmica em termos de História da Educação.

No capítulo 04 - Escrever, recortar, colar: "acervo de vivências" nos cadernos da professora luzia (1989-2010) (pp. 63-69) -, os artefatos são pesquisados como cultura material que acaba por tocar campos como a incerteza do acesso, os vínculos de afeto e as relações fecundas. Um subtítulo a este capítulo dá conta de buscar e encontrar a pessoa memoriada em suas caixas de arquivos (pp. 69-72).

Neste mesmo capítulo há uma tessitura de elaborações analíticas quanto a relação de intimismos em chave de relembranças (pp. 72-79) presente nos arquivos. Neles estão bem marcados palavras chave - palavras únicas (p. 79) como: mudança... infância... magia... sonho... mistério... Assim, a autora-pesquisadora reflete sobre a dimensão diferencial e unitária entre o ethos geracional e curva própria de vida presente em tais registros. Nesta parte da exposição sobre os arquivos - trecho que mereceu, inclusive, uma delicada inferência da autorapesquisadora -ocorre um relato como que de uma auto avaliação digna de nota pela sua abrangente temporalidade que percorre de 1950 a 2007 em um espécie de avaliação de percursos de vida e meditação profunda sobre a existência em que se registra: "o que eu fiz e o que gostaria de ter feito e não fiz", juntando um "passado tão perto e tão distante", narrando que "em pensamento retornei à infância" para "restaurar o sentido das experiências" e "reaprender como é possível ser feliz por tão pouco?", convidando-se ao "vasculhar dentro de si", para "re-inventar, cheiro de infância" uma vez que "existir talvez seja um pouco este reencontro com raízes atávicas" (p. 77).

É também deste quarto capítulo as outras "Faces de L." em que cotidiano, educação, cultura, política são relatados a si mesma pelo olhar da autora-fonte (p. 79) través de colagens, recortes e escritas dando margem a imaginar como aquelas produções tiveram circulação quase com vida própria uma vez que eles foram criados por vários anos e caminharam junto ao processo de amadurecimento de sua autora-fonte.

Um destaque especial a partir deste capítulo e nos seguintes é a existência de figuras que ajudam a levar para o campo a imagem o que antes se configurava como exercício imaginativo do leitor sobre os artefatos pesquisados, uma vez que cada figura exposta representa a materialidade do conteúdo da pesquisa neste ponto.

Para o quinto capítulo, a autora passa a destacar outro campo de empiria que é a Escola de Aplicação/ UFRGS, com estudos sobre os registros de uma professora polivalente, Isabel Loss, na temporalidade de quase de uma década - papéis de uma professora polivalente: miradas para as aulas de história (Colégio de Aplicação/UFRGS, 1978- 1986) (pp. 91-110). Com este material e arquivo analisam-se dados tão singulares quanto a descrição de aulas no Primeiro Grau de Ensino e outros dados com nuances de maior envergadura como a mudança curricular nos fins de 1970 e pouco mais da primeira metade da década de 1980, por exemplo, no tocante ao que que se entedia como ensino de Estudos Sociais em tempos da Ditadura Militar (1964-1984) e em tempos de reabertura democrática no Brasil (1985-...). Outras importantes 
reflexões a partir do material pesquisado dizem respeito a macro categorias, tais como: protocolos e cultura escolares (p. 96); notas avulsas sobre perfil discente e existência de projetos pedagógicos (p. 97); política e sentimentos (p. 98); Igreja, estado e Sexualidade (p. 100); metodologia e conteúdo curricular (p. 102); fabricação artesanal e manutenção de cadernos de planejamento (p. 107); divisão do tempo em componentes curriculares etc. (p. 108).

Deste capítulo cinco, ainda cabe referendar uma semi-digressão sobre a matéria Estudos Sociais que, inclusive, oportuniza ao leitor a viajar às suas próprias memórias escolares, tanto as estudantis quanto às docentes.

No sexto capítulo, aprofundam-se os estudos sobre o Professor Balduino Andreolla, em um processo de análise da micro-história e trajeto docente e de gestão deste educador por meio de seus arquivos pessoais ou a ele destinados. Aqui move-se um fio que ainda não estava tão explicito na trama desta obra que, agregado à função docente, também perpassa neste professor a função de gestor-reitor na FACED-UFRGS.

O início desse capítulo expõe o nível relacional entre autor originário dos arquivos e autora analítica do livro ora resenhado e a mesma liberdade e compromisso de ambos os autores com a produção e disseminação do conhecimento acadêmico-científico o que revela ainda o grau de liberdade quanto à utilização de tais memórias por parte da pesquisadora-autora sobre os arquivos pessoais do Professor-Reitor ao se tornarem matéria de estudo e análise da História, tendo como subtítulo: "Deixo inteira liberdade...": o arquivo pessoal do professor Balduino Andreolla (p. 111).

Esse capítulo também possui as narrativas e análises 'Entre guardar e doar: Dimensões do arquivo pessoal do Professor' (p. 114) que denota uma fina conexão entre objetivo da pesquisa e aporte individual em liberdade; As delicadezas deste arquivo pessoal: Bilhetes (p. 128); O intelectual Balduino Andreola: redes de pensamento e de ação (p. 129); e as Considerações Finais, concluído que os guardados ocorrem quando da aplicação de valor que a eles são atribuídos e dos quais eles estão imbuídos.

Quanto ao capítulo final, o sétimo, - Para não esquecer: apontamentos de uma professora, mãe, mulher e filha em agendas (1995-2014) (pp. 136-159) - ocorre um tipo documental raro... (p. 138) que são dezenove agendas, datadas entre 1995 e 2014, e que contém os registros de Beatriz Daudt Fischer, professora aposentada da UFRGS e UNISINOS, no qual se pode encontrar a trajetória e a ocupação de lugares, o cuidado do arquivamento, as evidência sutis ou flagrantes de mudança no percurso de vida e ainda certos apontamentos em diversas outras dimensões.

A continuidade deste capítulo tece análises e considerações em duas frentes concomitantes: uma com elucubrações conceituais sobre o instrumento agenda - que na etimologia latina (agendus/a/um) conceitua-se como gerúndio de agěre ou 'coisa que deve ser feita' - tais como: Agendas, para quê? (p. 141); As agendas, por elas mesmas (p. 143); Fim das agendas? (p. 158) e outra frente com refinamento de dados e interlocução entre pontos analíticos e a vida da pessoa pesquisada, refletida em suas escritas autorais: Traçados de si nos apontamentos: a professora, a Pesquisadora (p. 144); e Outros traçados de Beatriz, em meio às agendas (p. 150).

Na primeira frente de estudos, as agendas são também encaradas como facilitadoras da memória, como documento íntimo quase como um diário e registros de afizeres e programas que incidem e classificam-se como ego documento. Da segunda frente, com tais e tantos entrelaçamentos entre arquivos e autores, depreende-se que é um caminho natural a continuidade de produção de redes de afeto e mais vínculos de proximidade e interesse entre pesquisador/pessoas-fontes/pesquisador como fruto correlato desta abordagem e metodologia.

Tal qual a abertura desta obra através do Prefácio (pp. 05-07) de Maria Teresa Santos Cunha - UFSC, UDESC -, dado em Florianópolis, em janeiro 2021, também a sua finalização 
ocorre em chave de coerência e encontro entre conteúdo, forma e estilo, através do posfácio escrito por Maria Helena Camara Bastos, dado em Torres, no verão 2021.

'Percursos de um Arq-Vivo: entre arquivos e experiências na pesquisa em História da Educação' é um livro que tem potencial de remeter o leitor/pesquisador a suas próprias memórias com relação ao conteúdo exposto, pesquisado e narrado pela autora. Assim, por exemplo, aconteceu comigo na elaboração desta resenha...

Este livro é um exemplo de caminho possível a que outras instituições conheçam, animem-se e estruturem-se sobre como criar suas próprias memórias através de uma dupla valorização, memorial e arquivística, da pessoa e da Instituição, e como docentes, gestores e tantos outras pessoas podem e devem guardar, manter e preservar seus registros pessoais-profissionais em vista de contribuição potencial de serem e tornarem-se tanto memória como história que a muitos ajudará no futuro próximo ou distante através das malhas de interesse comum sobre temas, assuntos e conteúdos os mais diversos uma vez que nada escapa à possibilidade de historicidade. 